\title{
Learning radiotherapy: the state of the art
}

\author{
Gerard M. Walls ${ }^{1,2^{*}}$, Gerard G. Hanna ${ }^{2,3}$ (D) and James J. McAleer ${ }^{1,4}$
}

\begin{abstract}
Background: The last two decades have seen revolutionary developments in both radiotherapy technology and postgraduate medical training. Trainees are expected to attain competencies using a mix of experiential learning, formal postgraduate teaching, self-directed learning and peer education. Radiation (Clinical) Oncology is a recognised 'craft specialty' where the apprenticeship model of training is applicable. This scoping review examines the evidence in relation to how medical trainees learn radiotherapy.

Methods: A systematic search of MEDINE and EMBASE was undertaken to identify studies of trainee and/or trainer experience of radiotherapy learning published 1999-2018. Results pertaining to Medical Oncology, workforce trends, undergraduate radiotherapy exposure, academic training, global health, non-medical staff, health service infrastructure and recruitment to training programmes were not included.

Results: A total of 146 publications were included in the synthesis. Five themes were apparent through careful iterative analysis representing broadly inter-related issues. Most articles studied radiotherapy training from the perspective of the trainee doctor. Most literature reports results of observational, local or national surveys with a tightly defined scope. Considerable variation exists within hospitals, within countries, over time and between different curricular areas.
\end{abstract}

Conclusions: Medical education has not kept pace with changes in the field of radiotherapy and large differences are demonstrated in experience between trainees in different hospitals, countries and training stages. Interpersonal relationships, departmental organisation, and national curricula impact on training quality. Qualitative and quantitative research examining modern radiotherapy learning has been uncommon and uncoordinated, until recently. To date no single study has been designed to comprehensively assess a department's training scheme.

Keywords: Clinical oncology, Radiation oncology, Medical education, Training, Apprenticeship

\section{Background}

Clinical Oncology $(\mathrm{CO})$ is the medical discipline encompassing the non-surgical management of cancer, similar to the specialty of Radiation Oncology (RO) in countries such as USA, Canada and Ireland. Physicians in CO treat patients with both radiotherapy and systemic anti-cancer therapy (SACT) however. CO Specialty Trainees are expected to attain mandatory radiotherapy competencies

\footnotetext{
*Correspondence: g.walls@qub.ac.uk

'Cancer Centre Belfast City Hospital, Belfast Health \& Social Care Trust, Belfast, Northern Ireland

${ }^{2}$ Patrick G Johnston Centre for Cancer Research, Queen's University Belfast, Belfast, Northern Ireland

Full list of author information is available at the end of the article
}

over a period of 5 years in the UK, using a mix of experiential learning, formal postgraduate teaching, selfdirected learning and peer learning [1]. Developing skills in radiotherapy relies on workplace-based learning in particular, and CO is a recognised "craft specialty" [2-4] where the apprenticeship model of education is applicable $[5,6]$.

Over the past two decades, technological advances in radiation beam complexity and in imaging have revolutionised radiotherapy [7]. In working towards the Certificate of Completion of Training, trainees are expected to understand the underlying scientific principles of radiotherapy and become competent in modern treatment planning techniques [1]. Recent trainees have reported

(c) The Author(s). 2020 Open Access This article is licensed under a Creative Commons Attribution 4.0 International License, which permits use, sharing, adaptation, distribution and reproduction in any medium or format, as long as you give appropriate credit to the original author(s) and the source, provide a link to the Creative Commons licence, and indicate if changes were made. The images or other third party material in this article are included in the article's Creative Commons licence, unless indicated otherwise in a credit line to the material. If material is not included in the article's Creative Commons licence and your intended use is not permitted by statutory regulation or exceeds the permitted use, you will need to obtain permission directly from the copyright holder. To view a copy of this licence, visit http://creativecommons.org/licenses/by/4.0/ The Creative Commons Public Domain Dedication waiver (http://creativecommons.org/publicdomain/zero/1.0/) applies to the data made available in this article, unless otherwise stated in a credit line to the data. 
significant changes in the learning environment and it is possible that training quality has been adversely affected. Educationalists began to appreciate attrition of the classic apprenticeship relationship across medical specialties and purported this could be deleterious [8].

The aim of this scoping review is to characterise the status quo of the modern training landscape through the identification and synthesis of the existing literature on radiotherapy training. Understanding how trainees learn state-of-the-art radiotherapy will provide a starting point for educationalists with an interest in radiotherapy training, from which to plan future studies and improve local training.

\section{Methods}

\section{Review technique}

This study followed the accepted procedure for scoping reviews $[9,10]$, and reports results aligned with recommendations by Tricco et al. [11]. The scoping review methodology was chosen rather than classical systematic review for its advantages of being more inclusive and being suited to identifying knowledge gaps [12].

\section{Research team}

The research team comprised a CO Specialty Trainee (GW), and two CO Consultants (also known as Attending Physicians) involved in medical education (ME) (JM) and radiation research $(\mathrm{GH})$.

\section{Step 1: definition of the research question}

Radiotherapy is a craft wholly learned in the postgraduate setting and medical students' introduction to the specialty is restricted to an average of $10 \mathrm{~h}$ in European medical schools [13]. Training in radiotherapy therefore must include not just the technical nuances of the everexpanding range of techniques, but also basics, including scientific principles and radiotherapy department logistics. An investigation of what is currently understood about radiotherapy training broadly was undertaken, in order to inform future radiotherapy training studies aiming to improve local standards.

\section{Step 2: finding relevant literature.}

Two electronic databases (MEDLINE and EMBASE) were interrogated with a search strategy co-designed with a subject librarian on 1st August 2018. Search terms included "radiotherapy", "oncology", "education", "training", "apprentice", "postgraduate" and "residency". Results were restricted to the 20 years after 1998, when modern radiotherapy techniques began to be more widely adopted. Results pertaining to Medical Oncology, workforce trends, undergraduate radiotherapy exposure, academic training, global health, gender disparity, nonmedical staff, health service infrastructure and recruitment to training programmes were not included as they were outside the focus of the research. Only papers readily available in English were included. Citation lists were organised with Mendeley software (Mendeley, London, UK). Specifically, reports pertaining to undergraduate education were omitted as it was felt that meaningful radiotherapy training was administered virtually wholly in the postgraduate setting.

\section{Step 3: study selection}

Following the removal of duplicates, each author screened all abstracts retrieved independently, and rejected those articles not pertaining to the research question. The research team independently reviewed full-text copies of all screened papers to determine their suitability for inclusion in the analysis, based on the criteria listed in Table 1. In total 5 articles were available only as a conference abstract and were excluded, in keeping with scoping review methodology. The team worked collaboratively throughout the review to evaluate and classify articles, with open discussion around cases to reach a consensus where necessary.

\section{Step 4: charting the data}

The first author created a data extraction spreadsheet using Microsoft Excel (Microsoft, Redmond, USA) and populated demographic, methodological and outcome details. Articles were attributed keywords by one author (and cross-checked by another) to facilitate derivation of themes.

\section{Stage 5: collating, summarising and reporting the results}

Although not directly applicable to scoping review methodology, Preferred Reporting Items for Systematic Reviews and Meta-Analyses criteria guided the authors' approach where relevant, and a flow chart of the selection process is included (Fig. 1). A qualitative approach was used to organise the findings, with full-text review of groups of studies preceding summary statements reflecting key messages. This process was carried out by the lead author, and verified by both of the senior authors prior to summarising and reporting the results. Relevant manuscripts were grouped into themes which were felt to broadly represent inter-related issues.

\section{Results}

A total of 146 relevant articles were identified from the 269 search results. Study designs included surveys $(n=$ $62)$, educational intervention results $(n=30)$, organisation reports $(n=28)$, editorials $(n=15)$, pedagogical investigations $(n=8)$ and interviews $(\mathrm{n}=3)$. A small number of manuscripts featured a combination of these study types. Publications in ME in radiotherapy training have steadily risen in frequency in recent years (see 
Table 1 Eligibility criteria for selection of radiotherapy ME publications

\begin{tabular}{ll}
\hline Inclusion Criteria & Exclusion Criteria \\
\hline $\begin{array}{l}\text { Study participants were CO/RO Trainees or Consultants. } \\
\text { Study methodology employs qualitative or quantitative techniques. }\end{array}$ & $\begin{array}{l}\text { Study objectives primarily related to non-medical radiotherapy staff. } \\
\text { Studies relating to workforce trends, health service infrastructure and } \\
\text { recruitment issues. } \\
\begin{array}{l}\text { Study outcome(s) pertains to the quality of a component of } \\
\text { postgraduate training. }\end{array}\end{array}$ \\
$\begin{array}{ll}\text { Commentary articles or expert reviews. } \\
-\end{array}$ & $\begin{array}{l}\text { Publications related to academic training programmes. } \\
\text { Studies pertaining to undergraduate training. }\end{array}$ \\
\hline
\end{tabular}

Fig. 2). A minority of countries have published assessments of their radiotherapy programmes and the majority of publications resulted from studies undertaken in the USA. Figure 3 illustrates the proportions of studies from each of USA, Canada and UK, combined efforts two or more between nations, and other countries. Surveys were most frequently published in International Journal of Radiation Oncology*Biology*Physics $(n=18)$, Radiotherapy \& Oncology $(n=9)$ and Clinical Oncology $(n=7)$. The mean response rate for published surveys, where reported, was 55\% $(n=52)$. Surveys focussed on trainees alone $(n=30)$, trainers alone $(n=9)$, both trainers and trainees $(n=16)$ or a multitude of radiotherapy-related disciplines $(n=3)$. Over one third of articles were identified through citation lists. An additional 26 articles were included to introduce relevant background to topics presented. In assessing the available literature, themes emerged as documented with examples below. An exhaustive exploration of the sub- themes is included as a Supplementary Appendix, and this is summarised in Table 2 .

\section{Variation in training}

This theme was so titled as it encapsulates the shift in expectations and attitudes of trainers and trainees between different contexts, emphasising a lack of standardisation in training provision. Berriochoa et al. found that trainees reported leading more teaching sessions for trainees than reported by trainers and trainees perceived greater benefit from senior-led teaching than peer teaching, in contrast to trainer perceptions [14]. On the whole, trainees increase in confidence in specific competencies as their stage of training progresses eg radiological anatomy [15], although may be more achievable in $\mathrm{RO}$, compared with $\mathrm{CO}$ where a trainees' time is split between SACT and radiotherapy. A survey demonstrated that training opportunities and 'on call' burden are better in university hospitals than in non-academic centres

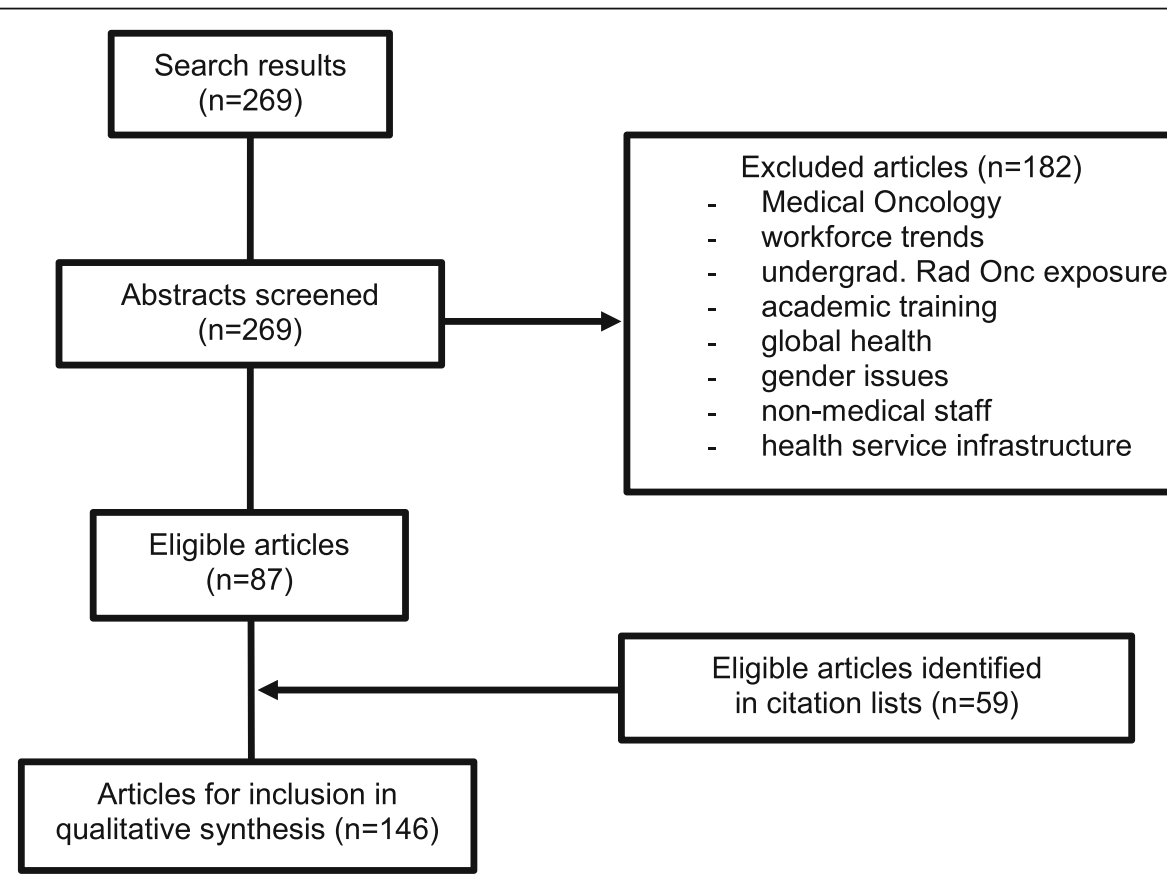

Fig. 1 PRISMA flow diagram for selection relevant radiotherapy ME publications 


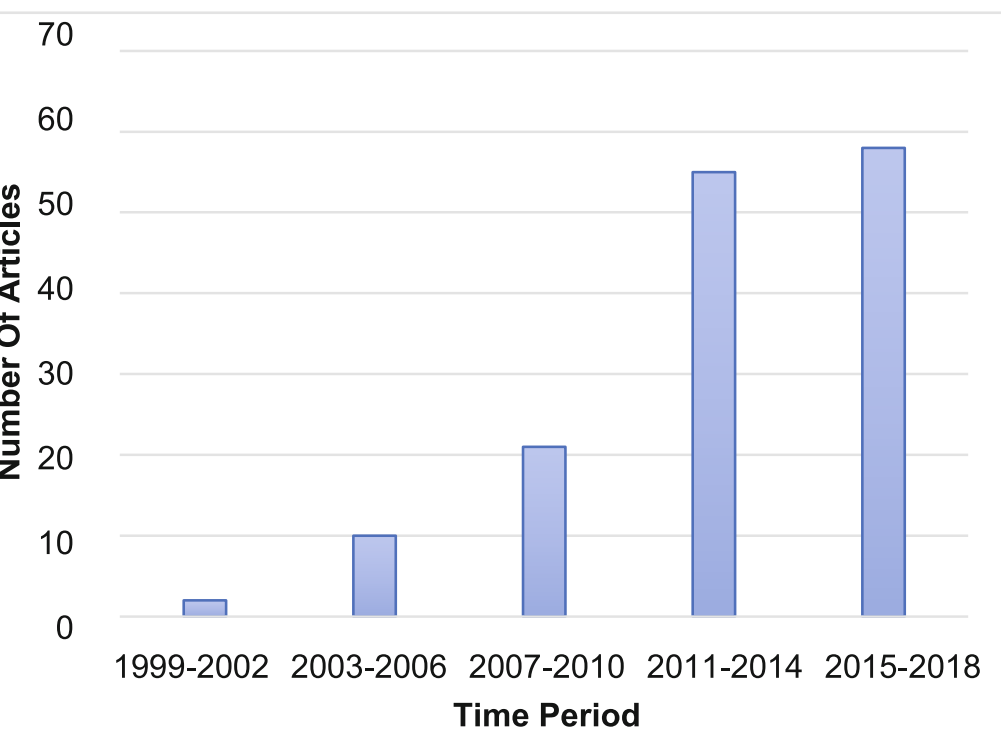

Fig. 2 Frequency of radiotherapy ME publications over the last two decades in 4-year bins

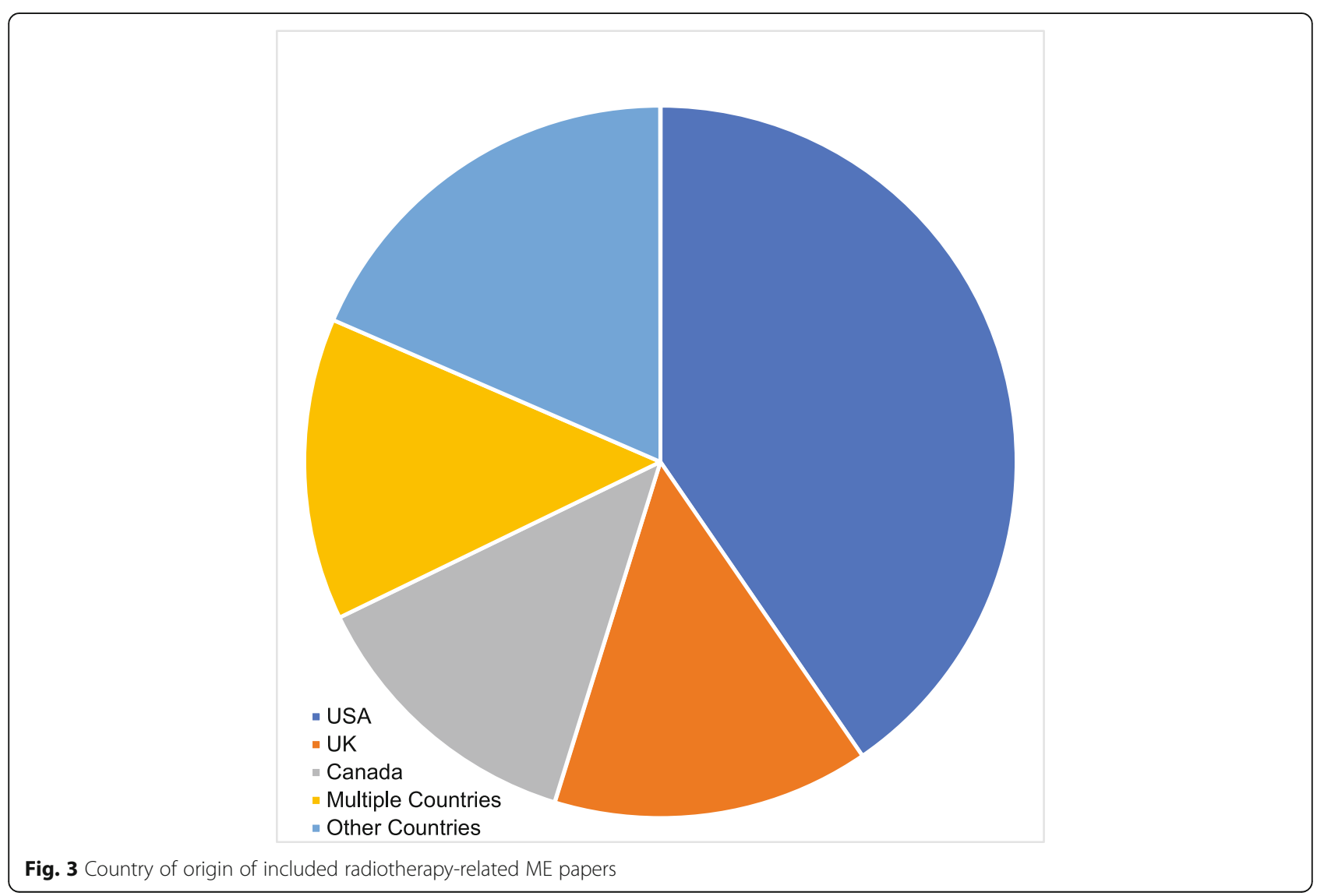


Table 2 Summary of themes from existing literature base

\begin{tabular}{llll}
\hline Themes & Sub-Themes & Definition of Sub-Theme & Example Findings \\
\hline $\begin{array}{l}\text { Variation in } \\
\text { Training }\end{array}$ & $\begin{array}{l}\text { Inter-role } \\
\text { variation }\end{array}$ & $\begin{array}{l}\text { Perspectives on specific issues are role- } \\
\text { dependent }\end{array}$ & $\begin{array}{l}\text { There can be a lack of congruence between trainer and } \\
\text { trainee accounts of how much time trainees devote to specific } \\
\text { activities in some studies }\end{array}$
\end{tabular}

Progression- $\quad$ Assessment of quality evolves as trainees related variation become more senior

Inter-centre Different centres in the same region may have variation very different resources for ME

International variation Resources vary greatly between centres in different countries

Temporal The multifactorial nature of training leads to variation

Activity-related variation

\section{Contributing Collegiality}

Factors

Mentorship

scheme

Peripheral units changes over time

\section{Pre-training} experience

National

curricula

Service provision

Strong and weak aspects of training co-exist within centres

Collegiality throughout different levels of the hierarchy improves training

Mentorship is highly valued by trainees

Create unique learning opportunities but impact on radiotherapy training is uncertain

Dedicated clinical opportunities are useful for acquiring preliminary principles in radiotherapy

Consensus principles for training have been agreed but uptake is variable

Administration An abundance of low-yield administration is

burden commonly reported by trainees

Job descriptions A lack of clarity in the expectations on trainees can affect their efficiency and integration

Study-leave Support for educational meetings is not budget

Underlying scientific principles accessible in some institutions

Service evolution Trainee experience is dependent on available radiotherapy techniques during rotations

Trainer-driven Involvement of trainees in the organisation of curriculum teaching is recognised to be beneficial

Economic and Training in radiotherapy is not protected from political

Impact of Training Quality

Career progression

Recruitment national economic events

Centres where training was undertaken can be important to interviewers for Consultant posts

Reputation for training quality is associated with competition for training positions

Burnout Poor training quality is associated with increased rates of burnout

Fellowship dependence Trainees may require post-programme training to compensate for inadequate experience

Academic aspiration

Online training tools

Anatomy instruction with less emphasis on quality of training trainees activities in some studies

Trainees may have a larger administrative burden in late training, but improve in confidence of radiology

Exposure to certain techniques, funding for external training and 'on call' burden may vary between centres

Expectations of time spent radiotherapy planning vary considerably between countries and continents

Adoption of legislation such as new working hours restrictions, may impact on training delivery

Trainees report greater competence for common procedures than techniques used infrequently

Collegiality amongst peer trainees and seniors contributes positively to learning

Value of mentors in $\mathrm{RO}$ in learning radiotherapy as well as navigating career

Less exposure to advanced radiotherapy technologies available outside main cancer hub possibly

Exposure to oncology-related and radiotherapy clinical scenarios prior to securing formal training post beneficial

Continental and global collaboratives have been set up with the aim of standardising radiotherapy training

Understaffing is an almost universal problem amongst centres and can affect training quality

Trainees in some countries spend up to $10 \mathrm{~h}$ per week undertaking activities without any educational benefit

The duality of training and delivering healthcare complicates the definition of clinical responsibilities

Local/regional policies can restrict some trainees from accessing external training

Inadequate delivery of core radiotherapy principles for building more clinical learning

Local uptake of emerging trends in clinical practice influence the training experience available to trainees

International reports have established the gains of involving trainees in the design and delivery of the curriculum

Countries have reported disrupted practical elements of training during previous national turmoil

A graduating trainee's level of experience carries significant weight at interviews for permanent posts

Trainees have been shown to rank posts by the reputed quality of training available at a centre

Burnout is more likely in TPDs and trainees where there is insufficient time for their respective educational roles

Fellowships may compensate for inadequately covered elements of curriculum or special interests

Academic ambition is reduced in those centres Centres with poorer quality radiotherapy training are associated with less academic aspirations amongst trainees

Online didactic modules and interactive atlases have been shown to be favourable

Integrated anatomical learning with scans, lectures and cadavers is effective 
Table 2 Summary of themes from existing literature base (Continued)

\begin{tabular}{|c|c|c|c|}
\hline Themes & Sub-Themes & Definition of Sub-Theme & Example Findings \\
\hline & & effective & \\
\hline & $\begin{array}{l}\text { Volume } \\
\text { delineation } \\
\text { lessons }\end{array}$ & $\begin{array}{l}\text { Dedicated contouring teaching is highly } \\
\text { sought after by trainees }\end{array}$ & $\begin{array}{l}\text { Small group and webinar-based are moderately effective, com- } \\
\text { mon methods of addressing trainee weaknesses }\end{array}$ \\
\hline & Trainee societies & $\begin{array}{l}\text { Societies provide space for like-minded trainees } \\
\text { to benefit from each other's experience and } \\
\text { ideas }\end{array}$ & $\begin{array}{l}\text { Countries with the greatest published outputs in CO/RO } \\
\text { medical education have national societies which develop } \\
\text { resources }\end{array}$ \\
\hline & Simulation & $\begin{array}{l}\text { Highly applicable in this technology-centric } \\
\text { specialty }\end{array}$ & $\begin{array}{l}\text { This costly educational method suits practical elements of } \\
\text { radiotherapy such as brachytherapy }\end{array}$ \\
\hline & Logbooks & Mixed views available, depending on format & $\begin{array}{l}\text { Logbooks have been championed in surgical specialties, with } \\
\text { which } \mathrm{RO} / \mathrm{CO} \text { can be compared in terms of training styles, but } \\
\text { are time-expensive }\end{array}$ \\
\hline & $\begin{array}{l}\text { Leadership } \\
\text { training }\end{array}$ & $\begin{array}{l}\text { Increasing emphasis is required in line with } \\
\text { other specialties, several model programmes in } \\
\text { RO }\end{array}$ & $\begin{array}{l}\text { Online, face-to-face and blended programmes have been } \\
\text { established for this increasingly recognised skill in } \mathrm{RO} / \mathrm{CO} \\
\text { clinicians }\end{array}$ \\
\hline & $\begin{array}{l}\text { Programmatic } \\
\text { training }\end{array}$ & $\begin{array}{l}\text { Organised themed sessions favourably ranked } \\
\text { by trainees, particularly for rarer clinical } \\
\text { scenarios }\end{array}$ & $\begin{array}{l}\text { Integrating seminars, lectures, departmental meetings and } \\
\text { electronic alerts over a period of time led to sustained } \\
\text { retention of learning }\end{array}$ \\
\hline & $\begin{array}{l}\text { Applied physics/ } \\
\text { radiobiology }\end{array}$ & $\begin{array}{l}\text { Practical demonstrations integrated with } \\
\text { lectures on challenging principles are } \\
\text { successful }\end{array}$ & $\begin{array}{l}\text { A teaching instrument combining practical and theoretical } \\
\text { elements of radiobiology and radiotherapy physics has been } \\
\text { designed }\end{array}$ \\
\hline & $\begin{array}{l}\text { Trainee-led } \\
\text { continuity clinic }\end{array}$ & $\begin{array}{l}\text { Benefits are available for both trainee learning } \\
\text { and patient care due to improved continuity }\end{array}$ & $\begin{array}{l}\text { Patient compliance was increased, trainees reported } \\
\text { satisfaction and trainers noted improved workflow and } \\
\text { documentation }\end{array}$ \\
\hline & $\begin{array}{l}\text { Inpatient } \\
\text { feedback }\end{array}$ & $\begin{array}{l}\text { Ward-based assessment with immediate } \\
\text { feedback involving patient commentary } \\
\text { insightful }\end{array}$ & $\begin{array}{l}\text { May improve specifically targeted behaviours amongst trainees } \\
\text { and improve trainee satisfaction }\end{array}$ \\
\hline & Induction & $\begin{array}{l}\text { Meaningful induction required for trainee to } \\
\text { gain maximum benefit from a rotation }\end{array}$ & $\begin{array}{l}\text { Trainers may be unaware of induction processes and under } \\
\text { rate their value in comparison to trainees }\end{array}$ \\
\hline & Device apps & $\begin{array}{l}\text { Increasing range of apps available although } \\
\text { their clinical validity is often unverified }\end{array}$ & $\begin{array}{l}\text { Apps may be used regularly each day by trainees, especially } \\
\text { for more technical tasks such as equivalent dose calculations }\end{array}$ \\
\hline \multirow{3}{*}{$\begin{array}{l}\text { Emerging } \\
\text { Pedagogical } \\
\text { Themes }\end{array}$} & $\begin{array}{l}\text { Interprofessional } \\
\text { teaching }\end{array}$ & $\begin{array}{l}\text { Mixed group teaching is widely viewed as } \\
\text { appropriate and highly valuable }\end{array}$ & $\begin{array}{l}\text { Concurrent training with Radiation Therapists has been shown } \\
\text { to be beneficial from the view of both trainers and trainees }\end{array}$ \\
\hline & $\begin{array}{l}\text { Tailored } \\
\text { assessments }\end{array}$ & $\begin{array}{l}\text { Novel, automated, embedded assessment tools } \\
\text { are achievable in this technology-centric } \\
\text { discipline }\end{array}$ & $\begin{array}{l}\text { Novel planning-based software with integrated feedback com- } \\
\text { ponents are effective in brachytherapy training }\end{array}$ \\
\hline & $\begin{array}{l}\text { Near-peer } \\
\text { teaching }\end{array}$ & $\begin{array}{l}\text { Content delivered by trainees for trainees is } \\
\text { regarded is highly valued }\end{array}$ & $\begin{array}{l}\text { Application of near-peer training in simulation-based learning } \\
\text { environments has been successfully undertaken }\end{array}$ \\
\hline
\end{tabular}

and financial support to varying degrees is available to facilitate trainee attendance at professional courses [16]. It was noted that the classification of a centre as academic depends on different criteria in different countries. Whilst most radiotherapy learning (RL) facets vary widely, exposure to plan evaluation is reported as difficult to acquire in most jurisdictions [17-21]. National surveys have demonstrated that perceptions of training fluctuate with time spent in training [22-25] and this pattern was observed in relation to less common tumour sites and emerging radiation techniques in particular. Such trends are likely to be explained by factors including survey learning amongst trainers, expanding access to radiotherapy technology, and organisational changes in postgraduate training nationally including hours rostered.

\section{Contributing factors}

This theme aggregates key areas currently making an appreciable difference to trainers and/or trainees in day-today workplace interactions. Collegiality amongst peer trainees and seniors contributes positively to learning $[17,26]$. Mentorship has regained popularity in ME literature recently, and the potential value of mentors in RO has been highlighted globally using various methodologies [27-30]. In an attempt to address the discrepancies in radiation-specific Oncology education for trainee doctors, the European Society of Therapeutic Radiation Oncology (ESTRO) designed a curriculum encompassing all essential elements of RL [31, 32]. By its nature, this largely ignores competing interests in SACT for CO trainees. European collaborators proposed guidelines for staffing, training resources and educational infrastructure 
but despite endorsement by the European Radiotherapy Board, guideline adherence has not been audited [33]. Service provision not only impacts trainees, but it has an effect on the performance of TPDs [34]. A European study reported greatest level of trainee agreement in relation to 'less bureaucracy' as a method of improving their RL [16]. The increasing technical complexity of radiotherapy and the highly specialised skills required by operators has meant that the uptake of many technologies is variable between centres [35]. Conventionally trainee involvement in the design of Specialty Training has not been routine, but the promotion of trainee opinion to provide constructive feedback has been recommended [36-38].

\section{Impact of training}

This section explore the downstream effects associated with these factors. Clinical training quality may be the leading factor in preference of RT centre for trainees, and in the context of a post deficit, better trainees may be recruited to centres with relatively better training quality [39]. A study of TPDs found correlation between a lack of time for educational activity and emotional exhaustion [34]. Survey-based evidence suggests that Fellowship training is used to compensate for inadequate experience during Specialty Training in areas of the curriculum, in addition to their intended purpose of gaining skill not accessible in their training [40].

\section{Improving training}

This theme summarises the available evidence of approaches incrementally improving specific aspects of training. Cohort studies of trainees exposed to an integrated programme of radiological, didactic and cadaveric demonstrations found that both knowledge and contouring performance were significantly improved [41-43]. RL comprising an interactive, small-group contouring demonstration following a didactic lesson in radiological anatomy of the head and neck was feasible and effective in the transfer of skills [44]. For gynaecological brachytherapy training, supervised trainee-performed clinical procedures have been followed up with simulated practice at a delayed timepoint by investigators [45]. Scrutiny of practical skill and subjective confidence level appeared to validate this competency-based approach. Modular teaching relating to leadership skills in the realm of RL have been successfully trialed [46]. 'Continuity of care'centred clinics operated by trainees have been successfully instigated in a US cancer centre, with observed benefits for both trainees and patients [47]. Such approaches may have more benefit for RO trainees who aren't usually involved in SACT, unlike CO trainees. A survey of trainer and trainee views regarding orientation revealed differences of opinion, for example, trainers were more likely to think trainees were ready to begin clinical work on day one, and trainers believed that a formal introductory curriculum was in place at their centre when it wasn't [48]. Trainers were less likely to believe that a formal induction made a trainee better prepared for clinical work; trainers and trainees had very different levels of agreement regarding the desired content of a useful introductory module. Another option considered by these investigational educators was offsite 'boot camp' training, which is commended for the removal of clinical distractions and increasing the social context of orientation.

\section{Emerging pedagogical themes}

'Emerging Pedagogical Themes' collects the educational paradigms on the horizon that seek to enhance training experience. Given the interprofessional collaboration involved in the patient radiotherapy journey, the feasibility and effectiveness of training doctors alongside Physicists and Radiation Therapist could be deemed unsurprising $[4,49-52]$. Statistical techniques were used to create a competency checklist for gynaecological brachytherapy [53] and advanced qualitative methodologies produced consensus target volumes for assessment of contours [54]. Near-peer teaching has been applied in CO informally historically, but also in newer contexts such as simulated and interprofessional training [51].

\section{Discussion}

Qualitative and quantitative research examining modern $\mathrm{RL}$ is limited. The senior-led decision making nature of Oncology has engendered an educational model of apprenticeship, where trainees learn through clinical encounters and technical aspects of RO shared with their clinical supervisor. As the apprenticeship model has become less suitable with the evolution of clinical radiotherapy, witnessed also in other medical disciplines [8] so clinical training requires renewed investment to protect training standards. This study has identified a surge in ME publications in $\mathrm{CO}$ and $\mathrm{RO}$ since 2011. A majority of the available literature reports findings from observational, local or national surveys with a tightly defined scope. Most articles were surveys of the trainee's perspective only. Five themes were apparent through careful iterative analysis representing broadly inter-related issues.

\section{Limitations}

The unsupervised element of this scoping enquiry, chosen to capture as much of the wide-ranging and separate relevant literature as possible, means that emerging themes received relatively equal scrutiny. More focussed future studies could increase the depth of the analysis of many areas, with a greater availability of evidence as it emerges. Whilst other medical specialties undergoing evolution may reconcile with some of the identified 
factors, it is likely that content specific to $\mathrm{RO} / \mathrm{CO}$ will limit the applicability. Furthermore, there may be differences in how the learning from this study can be applied between the $\mathrm{CO}$ and $\mathrm{RO}$ specialties, and articles relating to the interaction between radiotherapy and SACT training were not included in this study. Included studies were not subject to a rigorous assessment of study quality. This is an expected disadvantage of scoping review methodology, where data from a wide range of sources are accessed. The exploratory nature of the scoping review was felt to be justified given the lack of previous review papers. In addition, a small number of articles were noted to cover several areas, and it is anticipated that some areas were explored more than others during the synthesis. Over one third of articles were not identified directly in the search implying the search terms for future overviews should be carefully optimised in this diverse, expanding field. Initiatives existing purely in the 'grey literature' are likely to have been missed as this was not a traditional systematic review.

While RO and CO disciplines may be regarded as very similar with respect to clinical practice, there may be significant international variation in the circumstances of ME, in terms of policy, resource and attitude. Furthermore, there could be subtle intercontinental differences in the nomenclature and the predominant representation of USA, UK and Canada may restrict the applicability of results to other countries eg definition of academic centres. However, institutions which have not yet assessed their training may learn from the published experience of institutions which are actively developing their training programme. Articles identified and the results generated pertain virtually entirely to high income countries, restricting the applicability of this scoping exercise. It is anticipated that the global shortage in radiotherapy facilities and staffing in lower- and middle-income nations amplifies the challenges outlined in this study. Lastly, this study fails to address the impact of training in systemic therapy on the junior doctor's RL in those countries where $\mathrm{RO}$ is incorporated within $\mathrm{CO}$ training, compared to those in which it is not.

\section{Proposals}

The collated literature on contemporary CO ME has not been published previously. The scope of identified studies in this review capture elements of training quality, its determinants and impact, and both existing and novel methods of change. The authors' recommendation is that national training bodies should work towards the development of a consensus around ideal minimum standards for local training circumstances. As a minimum, additional formal ME resource will be required, for example, trainee and trainer ME Fellowships, support for postgraduate qualifications and practical resource such as journal subscriptions.

Topics could each serve as individual foci of study, which will be warranted for more complex issues. eg. simulation in $\mathrm{RO} / \mathrm{CO}$ ME. Coordination of studies through purpose-built national networks would facilitate concerted efforts on a large scale, creating a more robust dataset and increasing the impact of outputs. Equally, the themes drawn out from the literature in this study could represent a reasonable grounding for a fivepronged approach which training programme directors evaluating local $\mathrm{RO} / \mathrm{CO}$ training could centre data collection around, for example:

- Variation in training - is the training standardised between centres / teams / doctor grades?'

- Impact of training quality - "how many trainees get Consultant posts / burnout / academic roles?'

- Contributing factors - 'do we have a mentorship programme / study leave / trainee involvement?'

- Improving training - 'do trainees have a society / log book / adequate induction / online tools?'

- Emerging pedagogical themes - 'do we have novel local solutions for improving training?'

Although the paucity of CO ME research is being addressed globally, without a research network and framework, most facets of clinical training have not been thoroughly examined. ME research designs available to researchers include observational and interventional, and both qualitative and quantitative techniques. As outlined in the results, successful qualitative approaches include interviews, focus groups and questionnaires, and these add layered complimentary insights to familiar quantitative approaches such as questionnaires. It is anticipated that trainer and trainee perspective of local factors should guide the local study designs. The authors would beckon that efforts are made to publish all evaluations and initiatives in $\mathrm{RO} / \mathrm{CO} \mathrm{ME}$ to ensure findings can be included in future overview exercises. The welcome recent increase is probably secondary to improved awareness of the value of ME research, particularly through research collaboratives such as the Radiation Oncology Education Collaborative Study Group in the USA and curriculum development frameworks such as CanMEDS in Canada.

No studies have attempted to comprehensively assess a department's clinical training and it is likely that methodology such as institutional ethnography would be particularly applicable [55]. This technique is used in healthcare professional research to analyse the inner workings of a system of people linked by a common goal, using an "on the ground" approach. Institutional ethnography moves away from abstract hypotheses by 
encouraging the researcher to access people's actual practices, and it makes the case for reflexive learning about a system from an internal viewpoint as opposed to an external account. A smaller scale, 'mixed methods' approach may also reveal intrinsic factors [56]. In an increasingly pressurised system, it would be prudent to optimise mechanisms of CO ME to protect the strengths and build on weaknesses, proactively ensuring clinical training infrastructure prevails during the threat of service-driven reduced momentum.

\section{Conclusions}

ME has not kept pace with the rate of change in the field of radiotherapy and there are large differences in the experience of trainees in different hospitals, countries and training stage. Interpersonal relationships, departmental organisation, national curricula and government policies impact on training quality. Societal reports and interventional studies acknowledge these disparities and have proposed action plans. Further focussed research is urgently required to maintain training quality in this evermoving clinical discipline.

\section{Supplementary information}

Supplementary information accompanies this paper at https://doi.org/10. 1186/s12909-020-02054-Z.

Additional file 1. Supplementary index

\section{Abbreviations}

CO: Clinical Oncology; RO: Radiation Oncology; SACT: Systemic Anti-Cancer Therapy; M: Medical Education

\section{Acknowledgements}

The authors wish to thank Mr. Richard Fallis, School of Medicine, Dentistry and Biomedical Sciences Librarian at Queen's University Belfast, for his invaluable input during formation of the literature search strategy and Miss Andrea Flanagan for providing administrative assistance.

\section{Authors' contributions}

The search was co-designed by all three authors. GW organised results and inclusion/exclusion decisions were reviewed by both senior authors. GW drafted the study protocol, which was then edited iteratively with the input of $\mathrm{GH}$ and JM. All authors have read and approved the final version of this manuscript.

\section{Funding}

The lead researcher was supported by Friends of the Cancer Centre to undertake this research as part of a MSc Clinical Education at Queen's University Belfast, through the Dr. Gary McGowan Scholarship. This regional cancer charity had no role in the design, execution, analysis or reporting of this study.

\section{Availability of data and materials}

Search strategy defined in methods.

\section{Ethics approval and consent to participate}

Not applicable; no patients recruited or human/animal tissues involved.

\section{Consent for publication}

Not applicable; no patients recruited or human/animal tissues involved.

\section{Competing interests}

The authors declare that they have no competing interests.

\section{Author details}

${ }^{1}$ Cancer Centre Belfast City Hospital, Belfast Health \& Social Care Trust, Belfast, Northern Ireland. 'Patrick G Johnston Centre for Cancer Research, Queen's University Belfast, Belfast, Northern Ireland. ${ }^{3}$ Sir Peter MacCallum Department of Oncology, University of Melbourne, Melbourne, Australia. ${ }^{4}$ Centre for Medical Education, Queen's University Belfast, Belfast, Northern Ireland.

Received: 6 March 2020 Accepted: 27 April 2020

Published online: 11 May 2020

References

1. The Royal College of Radiologists. Specialty training curriculum for clinical oncology. London; 2016.

2. Gwynne S, Gilson D, Dickson J, McAleer S, Radhakrishna G. Evaluating target volume delineation in the era of precision radiotherapy: FRCR, Revalidation and Beyond. Clin Oncol. 2017;29(7):436-8.

3. Kosmin M, Brown S, Hague C, Said J, Wells L, Wilson C. Current views on clinical oncology training from the 2015 oncology registrars' forum survey. Clin Oncol. 2016;28(9):e121-5.

4. Barrett A, Rampling R, Kaye SB. Training for clinical oncology: experience in Glasgow 1987-1992. Clin Oncol. 1992;4(6):381-7.

5. The Royal College of Radiologists. Trainee induction pack for specialty training in clinical oncology. London; 2016.

6. The Royal College of Radiologists. Specialty training curriculum for clinical oncology. London; 2007.

7. Choudhury A, Budgell G, Mackay R, Falk S, Faivre-Finn C, Dubec M, et al. The future of image-guided radiotherapy. Clin Oncol. 2017;29(10):662-6.

8. Dornan T. Osler, Flexner, apprenticeship and "the new medical education". J R Soc Med. 2005;98(3):91-5.

9. Arksey H, O'Malley L. Scoping studies: towards a methodological framework. Int J Soc Res Methodol. 2005;8(1):19-32.

10. Colquhoun HL, Levac D, O'Brien KK, Straus S, Tricco AC, Perrier L, et al. Scoping reviews: time for clarity in definition, methods, and reporting. J Clin Epidemiol. 2014:67(12):1291-4.

11. Tricco AC, Lillie E, Zarin W, O'Brien KK, Colquhoun H, Levac D, et al. PRISMA extension for scoping reviews (PRISMA-SCR): checklist and explanation. Ann Intern Med. 2018;169(7):467.

12. Munn Z, Peters MDJ, Stern C, Tufanaru C, Mcarthur A, Aromataris E. Systematic review or scoping review? Guidance for authors when choosing between a systematic or scoping review approach; 2018. p. 1-7.

13. Ben $S$, Meijnders $P$, Jansen $N$, Lakosi F, Coucke $P$. The status of radiation oncology ( $\mathrm{RO}$ ) teaching to medical students in Europe. Clin Transl Radiat Oncol. 2019;17:40-6.

14. Berriochoa C, Weller M, Berry D, Reddy CA, Koyfman S, Tendulkar R. Program director and chief resident perspectives on the educational environment of US radiation oncology programs. Pract Radiat Oncol. 2017; 7(1):e65-70.

15. Matalon SA, Howard SA, Abrams MJ. Assessment of radiology training during radiation oncology residency. J Cancer Educ. 2019;34(4):691-5.

16. Dietzel CT, Jablonska K, Niyazi M, Gauer T, Ebert N, Ostheimer C, et al. Quality of training in radiation oncology in Germany: where do we stand? Strahlenther Onkol. 2018:194(4):293-302.

17. Franco P, Ciammella P, Peruzzo Cornetto A, De Bari B, Buglione M, Livi L, et al. The STYRO 2011 project: A survey on perceived quality of training among young Italian radiation oncologists. Med Oncol. 2013;30(4):729.

18. Casswell G, Shakir R, Macnair A, O'Leary B, Smith F, Rulach R, et al. UK training in clinical oncology: the trainees' viewpoint. Clin Oncol. 2018;30: 602-4.

19. Lopez Guerra JL, Isa N, Kim MM, Bourgier C, Marsiglia H. New perspectives in radiation oncology: Young radiation oncologist point of view and challenges. Reports Pract Oncol Radiother. 2012;17(5):251-4.

20. Likhacheva A, Mitin T, Khmelevsky E. The red beam: past, present, and future of radiation oncology in Russia. Int J Radiat Oncol Biol Phys. 2017 97(2):220-4

21. Celik OK. Health care reforms in Turkey and their impact on the field of radiation oncology. Int J Radiat Oncol Biol Phys. 2014;88(3):549-51.

22. Nabavizadeh N, Burt LM, Mancini BR, Morris ZS, Walker AJ, Miller SM, et al, Results of the 2013-2015 Association of Residents in radiation oncology 
survey of chief residents in the United States. Int J Radiat Oncol Biol Phys. 2015;94(2):228-34.

23. Gondi V, Bernard JR, Jabbari S, Keam J, De Amorim Bernstein KL, Dad LK, et al. Results of the 2005-2008 association of residents in radiation oncology survey of chief residents in the United States: clinical training and resident working conditions. Int J Radiat Oncol Biol Phys. 2011:81(4):1120-7.

24. Jagsi R, Buck DA, Singh AK, Engleman M, Thakkar V, Frank SJ, et al. Results of the 2003 Association of Residents in radiation oncology (ARRO) surveys of residents and chief residents in the United States. Int I Radiat Oncol Biol Phys. 2005;61(3):642-8.

25. Jagsi R, Chronowski GM, Buck DA, Kang S, Palermo J. Special report: results of the 2000-2002 association of residents in radiation oncology (arro) surveys. Int J Radiat Oncol Biol Phys. 2004;59(1):313-8.

26. Semrau R, Hansemann K, Adam M, Andratschke N, Brunner T, Heinzelmann $\mathrm{F}$, et al. Quality of training in radiation oncology in Germany: results of a 2006 survey. Strahlentherapie und Onkol. 2008;184(5):239-44.

27. Dhami G, Gao W, Gensheimer MF, Trister AD, Kane G, Zeng J. Mentorship programs in radiation oncology residency training programs: a critical unmet need. Int J Radiat Oncol Biol Phys. 2016;94(1):27-30.

28. Benstead K. What is valuable for specialist registrars to learn in order to become good consultant clinical oncologists? Clin Oncol. 2006;18(7):549-54.

29. Szumacher E, Warner E, Zhang L, Kane G, Ackerman I, Nyhof-Young J, et al. Ontario radiation oncology residents' needs in the first postgraduate yearresidents' perspective survey. Int J Radiat Oncol Biol Phys. 2007;69(2):512-7.

30. Ko HC, Kimple RJ. The resident individual development plan as a guide for radiation oncology mentorship. Int J Radiat Oncol Biol Phys. 2018;101(4): 786-8.

31. Eriksen JG, Beavis AW, Coffey MA, Leer JWH, Magrini SM, Benstead K, et al. The updated ESTRO core curricula 2011 for clinicians, medical physicists and RTTs in radiotherapy/radiation oncology. Radiother Oncol. 2012;103(1):1038.

32. Baumann M, Leer JWH, Dahl O, De Neve W, Hunter R, Rampling R, et al. Updated European core curriculum for radiotherapists (radiation oncologists). Recommended curriculum for the specialist training of medical practitioners in radiotherapy (radiation oncology) within Europe. Radiother Oncol. 2004;70(2):107-13.

33. Röttinger $E$, Barrett $A$, Leer JW. Guidelines for the infrastructure of training institutes and teaching departments for radiotherapy in Europe. Radiother Oncol. 2004;70(2):123-4.

34. Aggarwal S, Kusano AS, Carter JN, Gable L, Thomas CR, Chang DT. Stress and burnout among residency program directors in United States radiation oncology programs. Int J Radiat Oncol Biol Phys. 2015;93(4):746-53.

35. Routsis D, Staffurth J, Beardmore C, Mackay R. Education and training for intensity-modulated radiotherapy in the UK. Clin Oncol. 2010;22(8):675-80.

36. Dickson J, Liu D, Bloomfield D. Training in clinical oncology and the transition from trainee to consultant: results of the Royal College of Radiologists' 2015 post-certificate of completion of training survey. Clin Oncol. 2017;29(3):e64-71.

37. Wong DW, Sanghera P, Stevens AM, Grieve RJ. Survey of west midlands clinical oncology trainees. Clin Oncol. 2008;20(1):98.

38. Abdul N, Ward A, Hawkesford K. Acute oncology service and its implications on training: the specialty trainee's perspective. Clin Oncol. 2014;26(3):132-4.

39. Brower JV, Liauw SL, Reddy AV, Golden DW. Radiation oncology residency selection: a postgraduate evaluation of factor importance and survey of variables associated with job securement. Pract Radiat Oncol. 2017;7(6):42532.

40. Royce TJ, Katz MS, Vapiwala N. Training the radiation oncology workforce of the future: course correction to supply the demand. Int J Radiat Oncol Biol Phys. 2017;97(5):881-3.

41. D'Souza L, Jaswal J, Chan F, Johnson M, Tay KY, Fung K, et al. Evaluating the impact of an integrated multidisciplinary head \& neck competency-based anatomy \& radiology teaching approach in radiation oncology: a prospective cohort study. BMC Med Educ. 2014;14(1):1-10.

42. Jaswal J, D'Souza L, Johnson M, Tay K, Fung K, Nichols A, et al. Evaluating the impact of a Canadian national anatomy and radiology contouring boot camp for radiation oncology residents. Int I Radiat Oncol Biol Phys. 2015; 91(4):701-7.

43. Labranche L, Johnson M, Palma D, D'Souza L, Jaswal J. Integrating anatomy training into radiation oncology residency: considerations for developing a multidisciplinary, interactive learning module for adult learners. Anat Sci Educ. 2015;8(2):158-65.
44. Bekelman JE, Wolden S, Lee N. Head-and-neck target delineation among radiation oncology residents after a teaching intervention: a prospective, blinded pilot study. Int J Radiat Oncol Biol Phys. 2009;73(2):416-23.

45. Zhao $S$, Francis $L$, Todor D, Fields EC. Proficiency-based cervical cancer brachytherapy training. Brachytherapy. 2018 Jul;17(4):653-9.

46. Adleman J, Niglas M, Millar BA. Leadership education in radiation oncology residency training. Int J Radiat Oncol. 2017;99(2):E120-1.

47. Yoo SK, Bian SX, Lin E, Batth SS, Ng LW, Andrade J, et al. Development of a radiation oncology resident continuity clinic to improve clinical competency and patient compliance. Int J Radiat Oncol Biol Phys. 2018;100(3):551-5.

48. Gunther JR, Jimenez RB, Yechieli RL, Parekh A, Berman AT, Braunstein SE, et al. Introductory radiation oncology curriculum: report of a National Needs Assessment and multi-institutional pilot implementation. Int J Radiat Oncol Biol Phys. 2018;101(5):1029-38.

49. Tan K, Bolderston A, Palmer C, Millar BA. "We are all students:" an interprofessional education approach to teaching radiation oncology residents. J Med Imaging Radiat Sci. 2011;42(4):183-8.

50. Hendee WR. Learning physics in radiation oncology. Int J Radiat Oncol Biol Phys. 2007;68(1):4-6

51. Brown LC, Laack TA, Ma DJ, Olivier KR, Laack NN. Multidisciplinary medical simulation: a novel educational approach to preparing radiation oncology residents for oncologic emergent on-call treatments. Int J Radiat Oncol Biol Phys. 2014;90(3):705-6.

52. Giuliani M, Gillan C, Wong O, Harnett N, Milne E, Moseley D, et al. Evaluation of high-fidelity simulation training in radiation oncology using an outcomes logic model. Radiat Oncol. 2014;9(1):1-7.

53. Quick A, Walker C, Martin D. Competency Evaluation for Gynecologic Brachytherapy for Radiation Oncology Residents. Brachytherapy. 2017;16(3, Supplement):S62.

54. Hallock A, Bauman G, Read N, D'Souza D, Perera F, Aivas I, et al. Assessment and improvement of radiation oncology trainee contouring ability utilizing consensus-based penalty metrics. J Med Imaging Radiat Oncol. 2012;56(6): 679-88.

55. Kearney GP, Corman MK, Hart ND, Johnston JL, Gormley GJ. Why institutional ethnography? Why now ? Institutional ethnography in health professions education. Perspect Med Educ. 2019;8(1):17-24.

56. Walls G, McAleer J, Hanna G. Perception of modern radiotherapy learning: study protocol for a mixed methods analysis of trainees and trainers at a United Kingdom cancer centre. BMJ Open. 2020;in press.

\section{Publisher's Note}

Springer Nature remains neutral with regard to jurisdictional claims in published maps and institutional affiliations.

Ready to submit your research? Choose BMC and benefit from:

- fast, convenient online submission

- thorough peer review by experienced researchers in your field

- rapid publication on acceptance

- support for research data, including large and complex data types

- gold Open Access which fosters wider collaboration and increased citations

- maximum visibility for your research: over $100 \mathrm{M}$ website views per year

At BMC, research is always in progress.

Learn more biomedcentral.com/submissions 